Check for updates

Cite this: RSC Adv., 2018, 8, 35211

Received 27th August 2018

Accepted 9th October 2018

DOI: $10.1039 / c 8 r a 07140 c$

rsc.li/rsc-advances

\section{Evaluation of xylooligosaccharide production from residual hemicelluloses of dissolving pulp by acid and enzymatic hydrolysis $\uparrow$}

\author{
Yuanyuan Wang, ${ }^{a}$ Xuefei Cao, (D) *a Ruochen Zhang, ${ }^{a}$ Lin Xiao, ${ }^{b}$ Tongqi Yuan, ${ }^{a}$ \\ Quentin Shic and Runcang Sun (D)*a
}

\begin{abstract}
Xylooligosaccharides (XOS) are useful food and pharmaceutical additives, which can be produced from various xylans. However, the XOS prepared from lignocellulosic materials are difficult to purify due to the complexity of the degradation products. Thus, hemicelluloses with a high-purity will be the preferred feedstock for XOS production. In this work, acid hydrolysis and enzymatic hydrolysis were applied to prepare XOS from the residual hemicelluloses of the dissolving pulp. The results showed that the highest XOS yield (45.18\%) obtained from the acid hydrolysis was achieved with $1 \%$ sulfuric acid at $120^{\circ} \mathrm{C}$ for $60 \mathrm{~min}$, and xylohexaose accounted for $47 \%$ of the XOS. For enzymatic hydrolysis, under optimal conditions, the highest XOS yield of $42.96 \%$ was observed, and xylobiose and xylotriose comprised $90.5 \%$ of the XOS. It is suggested that the distribution of the XOS could be controlled significantly according to the enzymatic or acid hydrolysis conditions used.
\end{abstract}

\section{Introduction}

Generally, XOS are a mixture of neutral oligosaccharides made up of two to ten xylose units linked by $\beta-1,4$ bonds. ${ }^{1,2}$ XOS have various features in common, including non-toxicity, nondigestibility, low available energy, low sweetness, and so on. ${ }^{3}$ Furthermore, XOS have many biological properties, such as immunomodulatory activity, anti-cancerous activity, antimicrobial activity, blood- and skin-related effects, antiallergy properties, anti-infection properties, anti-inflammatory properties, etc. ${ }^{4}$ Previous reports showed that XOS can improve the intestinal microbial environment by increasing the number of bifidobacteria, which promote metabolism and reduce the risk of colon cancer. ${ }^{5,6}$ Additionally, XOS can effectively improve the blood ammonia levels in patients with liver cirrhosis. ${ }^{7}$ Nowadays, XOS have been widely used as ingredients for functional foods to improve bowel function, lipid metabolism and calcium absorption, prevent tooth decay, increase the presence of beneficial bacteria, etc. ${ }^{5,8,9}$

Given the importance of XOS, the production of XOS from various lignocellulosic materials by different methods has been extensively explored over the last decade. ${ }^{10-20}$ Typically, XOS can

\footnotetext{
${ }^{a}$ Beijing Key Laboratory of Lignocellulosic Chemistry, Beijing Forestry University, Beijing, 100083, China.E-mail: caoxuefei@bjfu.edu.cn; rcsun3@bjfu.edu.cn

${ }^{b}$ Shandong Longlive Bio-Technology Co., Ltd., Shandong 251200, China

cjining Mingsheng New Materials Co., Ltd., Xinglong Industrial Park, Yanzhou District, Jining City, Shandong Province, 272101, China

$\dagger$ Electronic supplementary information (ESI) available. See DOI: 10.1039/c8ra07140c
}

be produced from various xylans by chemical methods, enzymatic hydrolysis or a combination of chemical and enzymatic treatments. ${ }^{4}$ Álvarez et al. ${ }^{11}$ collected the hemicelluloses from the steam explosion pretreated wheat straw and further investigated the obtained hemicelluloses for XOS production by enzymatic hydrolysis. The results indicated that over $90 \%$ xylans could be transformed into XOS by using endo-xylanase and $\beta$-glucosidase. Bian et al. ${ }^{15}$ explored the production of XOS from sugarcane bagasse hemicelluloses by microwave-assisted acid hydrolysis, and the maximum XOS yield of $290.2 \mathrm{mg} \mathrm{g}^{-1}$ hemicelluloses was obtained with $0.24 \mathrm{M} \mathrm{H}_{2} \mathrm{SO}_{4}$ for $31 \mathrm{~min}$. Yang et al. ${ }^{19}$ studied the production of XOS from corncob by a combination of acid pretreatment and enzymatic hydrolysis. The results showed that the cumulative yield of XOS after enzymatic hydrolysis was close to $67.7 \mathrm{~g} / 100 \mathrm{~g}$ (based on xylan in raw material). However, the isolation and purification of the XOS from the complex hydrolysate of biomass containing the lignin is difficult and costly.

Dissolving pulp is a highly purified pulp with a high cellulose content (95-98\%) and very low hemicelluloses and lignin content, which can be used to manufacture various cellulosebased products, such as cellulose ethers, cellulose esters, viscose fiber, etc. $^{21-23}$ With the increasing demand for dissolving pulp, large quantities of chemical pulp were used to prepare dissolving pulp for viscose fiber production. ${ }^{22,24}$ Thus, large amounts of hemicelluloses were generated from the alkali extraction stage of the chemical pulp. These hemicelluloses can be easily separated from the alkali solution by acidification or membrane filtration to give hemicelluloses with a high purity and uniform structures. These high-purity hemicelluloses 
extracted from the dissolving pulp are promising candidate for XOS production. To date, only few studies investigated the production of XOS from the hemicelluloses of the dissolving pulp..$^{25,26}$

In this work, the structural properties of the hemicelluloses extracted from the dissolving pulp were first characterized by NMR. Then, the hemicelluloses were hydrolyzed by acid and xylanase, respectively, under different conditions to obtain XOS. The XOS yields and the products distribution were comparatively evaluated during the acid hydrolysis and enzymatic hydrolysis processes. The effects of sulfuric acid concentration, hydrolysis temperature, and reaction time on the XOS yield were investigated in acid hydrolysis process. The influences of enzyme concentration and incubation time on the yield of XOS were studied in the process of enzymatic hydrolysis.

\section{Materials and methods}

\subsection{Materials}

The xylan-rich hemicelluloses extracted from the dissolving pulp were kindly provided by a viscose fiber mill (Xinjiang Fu Lida Fiber Co. Ltd, China). A typical production process for the hemicelluloses from the chemical pulp was conducted in three steps: (i) the pulp boards were soaked in aqueous alkali to dissolve the hemicelluloses, and the cellulose-rich solid was separated from the mixture; (ii) the above solution was treated by membrane filtration to recover most of the alkaline and water, resulting in concentrated hemicelluloses solutions; (iii) sulfuric acid was added to the concentrated hemicelluloses solutions to precipitate the hemicelluloses. ${ }^{26}$ Xylanase was kindly supplied by Utel biochemical Co. Ltd. Solvents and reagents were all of analytical grade and used as received.

\subsection{Acid hydrolysis}

The hemicelluloses $\left(\begin{array}{ll}1.0 & \mathrm{~g}\end{array}\right)$ were suspended in different concentrations of dilute sulfuric acid solution with a solid to liquor ratio of $1: 20\left(\mathrm{~g} \mathrm{~mL}^{-1}\right)$ in $35 \mathrm{~mL}$ high-pressure flask. The reaction was carried out with different acid concentrations $(0.1$, $0.3,0.7,0.9,1.0,1.2,1.5$, and $2.0 \mathrm{wt} \%)$ at moderate temperatures $\left(70,90,105,120\right.$, and $\left.135{ }^{\circ} \mathrm{C}\right)$ for the scheduled times $(15$, 30, 45, 60, and $75 \mathrm{~min}$ ) under stirring. As soon as the acid hydrolysis was completed, the reactant was cooled to room temperature for further analysis. The yields of xylose and XOS, including xylobiose (X2), xylotriose (X3), xylotetraose (X4), xylopentaose (X5), and xylohexaose (X6), were further detected. All experiments were performed in duplicate, and the results were averaged.

\subsection{Enzymatic hydrolysis}

The hemicelluloses were subjected to enzymatic hydrolysis by endo-xylanase in $250 \mathrm{~mL}$ conical flasks. The concentration of hemicelluloses was adjusted to $2 \mathrm{wt} \%$. In order to optimize the production of XOS by the endo-xylanase, different enzymatic hydrolysis times $(1,2,6,8,10,12,20$, and $24 \mathrm{~h})$ and enzyme dosages $\left(50,80,120\right.$, and $150 \mathrm{IU} \mathrm{g}^{-1}$ substrate) were evaluated. The enzymatic hydrolysis was carried out at $\mathrm{pH} 5$ and $50{ }^{\circ} \mathrm{C}$ in a $50 \mathrm{mM}$ sodium acetate buffer solution in the incubator with the shaking speed of $150 \mathrm{rpm}$. At certain time intervals, samples were taken and boiled at $100{ }^{\circ} \mathrm{C}$ for $5 \mathrm{~min}$ to inactivate the enzyme. After that, the content of xylose and XOS in the hydrolysate was quantified.

\subsection{Analytical methods}

The compositions of hemicelluloses were determined according to the standard laboratory analytical procedures from the National Renewable Energy Laboratory (NREL/TP-510-42618). ${ }^{27}$ Released monosaccharide, uronic acid and oligosaccharide were quantified by high-performance anion exchange chromatography (HPAEC, Dionex ICS 3000) using a CarbopacTM PA100 column $(4 \times 250 \mathrm{~mm}$, Dionex $)$ with a PA-100 guard column $(4 \times 50 \mathrm{~mm}$, Dionex $) .{ }^{17}$ The amount of hexoses and pentoses is multiplied by a constant factor of 0.9 and 0.88 , respectively, to obtain the content of sugars in polymeric form. The by-products were examined using high-performance liquid chromatography (HPLC, Agilent 1200 series, US) with the method described by a previous literature. ${ }^{28}$ The molecular weights of hemicelluloses were determined by gel permeation chromatography (GPC) with a refraction index detector using a PL aquagel-OH $50(300 \times 7.7 \mathrm{~mm})$ column. The column was operated at $30{ }^{\circ} \mathrm{C}$, and eluted with $0.02 \mathrm{M} \mathrm{NaCl}$ in $0.005 \mathrm{M}$ sodium phosphate buffer $(\mathrm{pH}=7.5)$ at a flow rate of 0.5 $\mathrm{mL} \mathrm{min}^{-1}$. All the hemicellulosic samples $(4 \mathrm{mg}$ ) were dissolved in $2 \mathrm{~mL}$ of sodium phosphate buffer $(\mathrm{pH}=7.5)$. PL pullulan polysaccharide standards (peak average molecular weights of 783, 12 200, 100 000, 1600 000, Polymer Laboratories Ltd.) were used to calibrate the data of GPC. The solution-state NMR spectra of the samples were recorded on a Bruker NMR spectrometer (AVIII, $400 \mathrm{MHz}$, Germany) according to the previous report. ${ }^{29}$ The XOS obtained from the acid and enzymatic hydrolysis were analyzed by HPAEC according to the procedure described in a previous publication. ${ }^{15}$ The XOS and xylose yield was calculated by following equations:

$$
\begin{aligned}
\text { XOS yield }(\%)= & \frac{(\mathrm{X} 2+\mathrm{X} 3+\mathrm{X} 4+\mathrm{X} 5+\mathrm{X} 6) \text { in hydrolysate }(\mathrm{g})}{\text { xylan in hemicelluloses }(\mathrm{g})} \\
& \times 100 \%
\end{aligned}
$$

$$
\text { Xylose yield }(\%)=\frac{\text { xylose in hydrolysate }(\mathrm{g})}{\text { xylan in hemicelluloses }(\mathrm{g})} \times 100 \%
$$

\section{Results and discussion}

\subsection{Physicochemical properties of the hemicelluloses extracted from the dissolving pulp}

The determination of the physicochemical properties of the hemicelluloses is critical for the XOS production. ${ }^{30}$ The hemicelluloses extracted from the dissolving pulp were characterized using GPC (Table S1†), ${ }^{1} \mathrm{H}$ NMR (Fig. S1 (Fig. S2 $\dagger$ ). Additionally, more detailed structural information was analyzed by the 2D-HSQC NMR technique (Fig. 1). The 


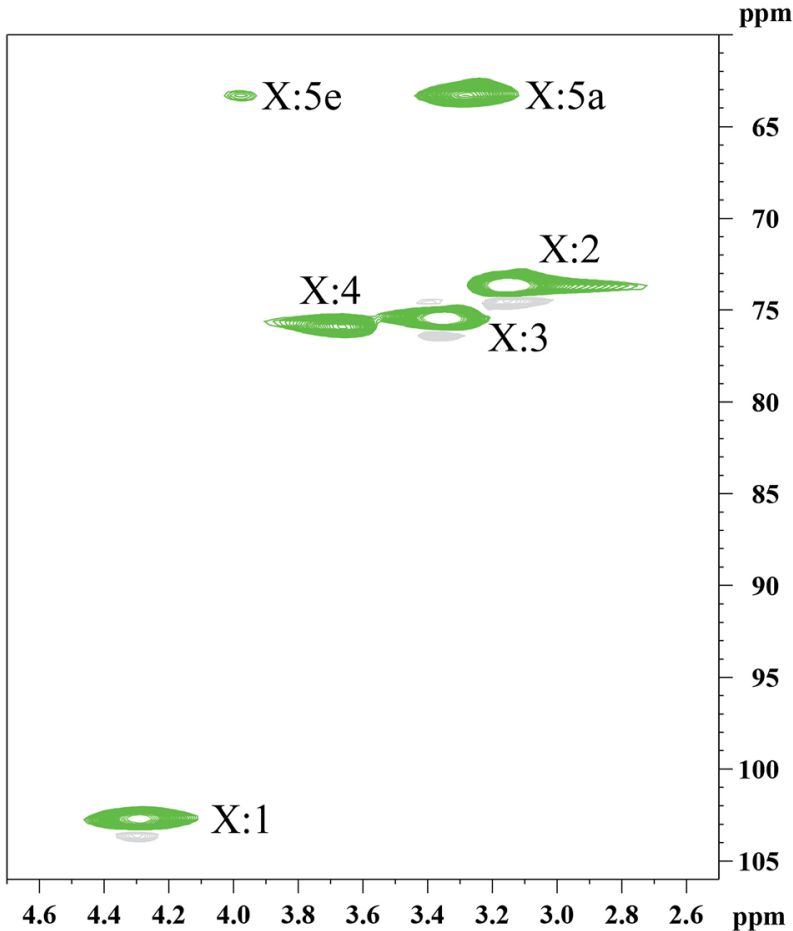

Fig. 1 2D-HSQC NMR spectrum of the hemicelluloses extracted from the dissolving pulp

chemical composition of the hemicelluloses was determined by HPAEC, and the results were presented in Table 1. Clearly, the hemicelluloses were mainly composed of xylan $(82.04 \%)$, and a small amount of glucose, galactose, arabinose, and glucuronic acid was also detected. The weight-average molecular weight $\left(M_{\mathrm{w}}\right)$ and polydispersity index $\left(M_{\mathrm{w}} / M_{\mathrm{n}}\right)$ of hemicelluloses was $14343.5 \mathrm{~g} \mathrm{~mol}^{-1}$ and 1.54 , respectively, implying that the hemicelluloses were relatively uniform polymers. The major cross-signals at $102.4 / 4.30,73.6 / 3.19,75.1 / 3.37,75.8 / 3.68,63.3 /$ 3.99, and 63.3/3.27 ppm observed in the HSQC spectrum of the hemicelluloses, are originated from the $\mathrm{C}_{1}-\mathrm{H}_{1}, \mathrm{C}_{2}-\mathrm{H}_{2}, \mathrm{C}_{3}-\mathrm{H}_{3}$, $\mathrm{C}_{4}-\mathrm{H}_{4}, \mathrm{C}_{5 \mathrm{eq}}-\mathrm{H}_{5 \mathrm{eq}}$, and $\mathrm{C}_{5 \mathrm{ax}}-\mathrm{H}_{5 \mathrm{ax}}$ of the $(1 \rightarrow 4)$-linked $\beta$-D-Xylp units, respectively. ${ }^{31}$ The results indicated that the hemicelluloses extracted from the dissolving pulp were mainly comprised of $(1 \rightarrow 4)$-linked $\beta$-D-xylans.

\subsection{Acid hydrolysis of the hemicelluloses for XOS production}

The compositions of the hydrolysate from the hemicelluloses were determined by HPAEC. It should be noted that the content of XOS was only determined from X2 to X6 because of the lack of the XOS standard larger than X6..$^{15,32}$ The effects of reaction conditions on the XOS and xylose yields during the acid hydrolysis process are presented in Fig. 2. The yields of the XOS and xylose under different sulfuric acid concentrations at $120{ }^{\circ} \mathrm{C}$ for $60 \mathrm{~min}$ are shown in Fig. 2a and d. It was observed that the content of X6 was much higher than other XOS when the acid concentration was lower than $1.5 \%$. However, results from Zhang et al. showed that the $\mathrm{X} 4$ content was the highest one when acetic acid was used at $120{ }^{\circ} \mathrm{C}$ for $30 \mathrm{~min} .{ }^{25}$ It suggested that the distribution of the XOS could be varied significantly with the acid used. ${ }^{12}$ The content of $\mathrm{X} 4, \mathrm{X} 5, \mathrm{X} 6$, and total $\mathrm{XOS}(\mathrm{X} 2+\mathrm{X} 3+\mathrm{X} 4+\mathrm{X} 5+\mathrm{X} 6)$ in hydrolysate increased with the increase of the sulfuric acid concentration from 0.1 to $1 \%$, and then decreased when the acid concentration was higher than $1 \%$, while the yields of xylose, $\mathrm{X} 2$, and $\mathrm{X} 3$ increased continuously with the increase of the acid concentration. This indicated that the hemicelluloses first degraded into XOS with relatively high DP values during the acid hydrolysis process, and then these XOS further hydrolyzed into XOS with low DP values and xylose. The degradation of the hemicelluloses and the formation of XOS and xylose are closely related to the acid concentration. The highest yield of XOS (45.18\%) was achieved with $1 \%$ sulfuric acid at $120{ }^{\circ} \mathrm{C}$ for $60 \mathrm{~min}$.

The effect of the reaction time of acid hydrolysis on the yields of XOS and xylose at $120^{\circ} \mathrm{C}$ with $1 \%$ sulfuric acid is illustrated in Fig. $2 \mathrm{~b}$ and e. It was found that the major component of the XOS was still X6. The total XOS yield increased gradually as the hydrolysis time increased from 15 to $60 \mathrm{~min}$, but it began to decrease when the reaction time extended to $75 \mathrm{~min}$. Meanwhile, similar trend was also observed for X6. However, the yield of xylose increased significantly with the prolonging of the reaction time. Obviously, a suitable reaction time was required to achieve a high yield of XOS. ${ }^{33}$ In this work, the optimal reaction time for the acid hydrolysis of hemicelluloses at $120^{\circ} \mathrm{C}$ with $1 \%$ sulfuric acid was $60 \mathrm{~min}$. Additionally, the influence of the reaction temperature on the XOS yield was also explored at constant acid concentration (1\%) and reaction time (60 min) and the results are shown in Fig. $2 \mathrm{c}$ and $\mathrm{f}$. It was found that when the temperature was lower than $120^{\circ} \mathrm{C}$, the yield of XOS was increased with the reaction temperature. However, when the temperature was beyond $120^{\circ} \mathrm{C}$, the total XOS yield declined from $45.18 \%\left(120^{\circ} \mathrm{C}\right)$ to $37.61 \%\left(135^{\circ} \mathrm{C}\right)$, and the yield of xylose dramatically increased from 18.78 to $66.13 \%$. It suggested that a relatively high yield of XOS could be obtained at $120^{\circ} \mathrm{C}$ under the given conditions. Therefore, in this work, an optimized XOS yield by acid hydrolysis could be obtained at $120{ }^{\circ} \mathrm{C}$ with $1 \%$ sulfuric acid for $60 \mathrm{~min}$.

\subsection{Enzymatic hydrolysis of the hemicelluloses for XOS production}

Enzymatic hydrolysis is a relatively mild method for the production of mono- and oligosaccharides from polysaccharides. It has been reported that considerable yield of XOS

Table 1 The chemical composition of the hemicelluloses extracted from the dissolving pulp

\begin{tabular}{llllllll}
\hline Composition & Xylan & Glucan & Galactan & Arabinan & Glucuronic acid & Ash & Klason lignin \\
\hline Concentration (\%) & 82.04 & 3.24 & 0.16 & 0.1 & Trace & 3.26 & 1.49
\end{tabular}



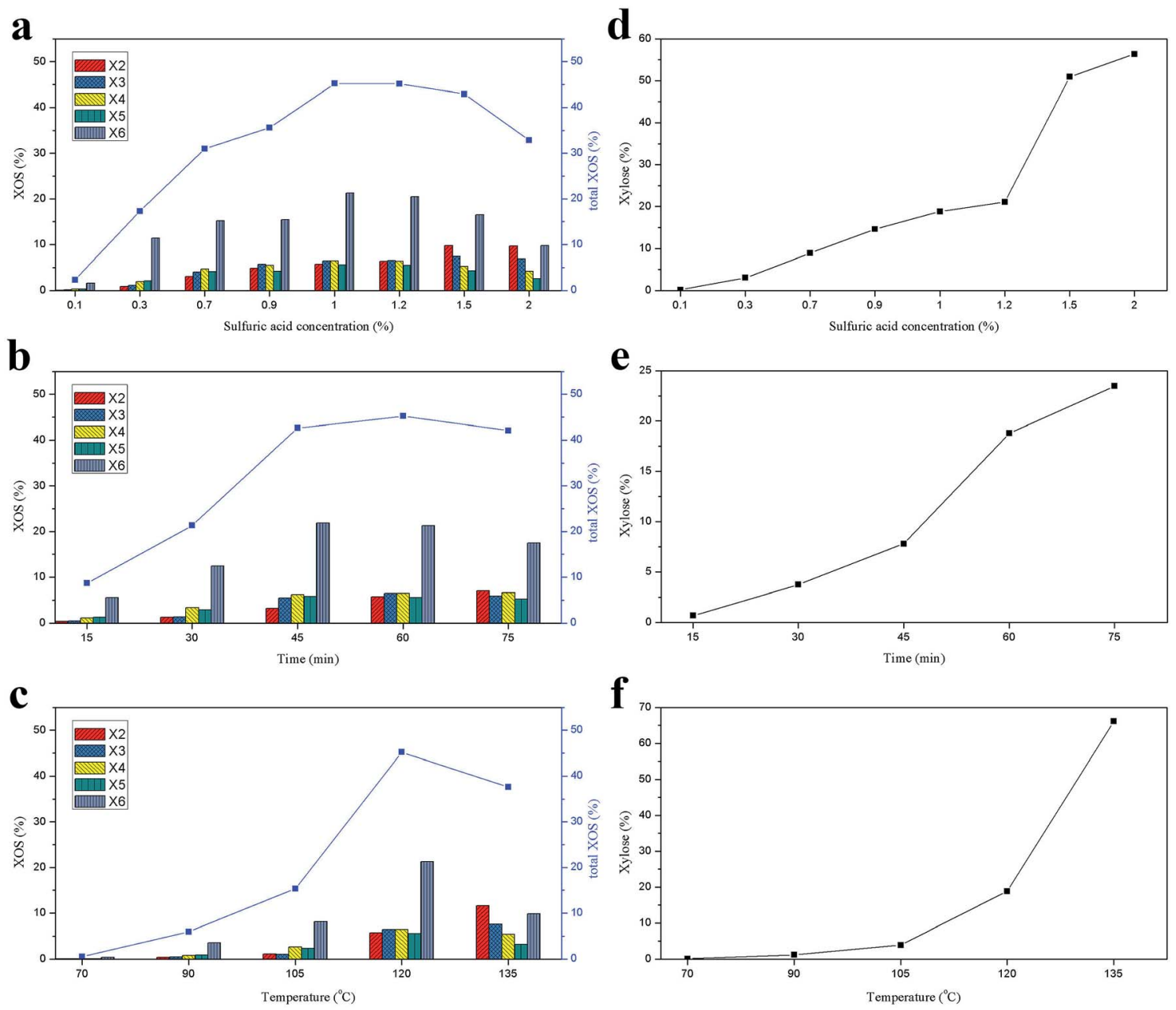

Fig. 2 Effects of sulfuric acid concentration ( $a$ and d), reaction time ( $b$ and e), and reaction temperature (c and f) on the yields of XOS and xylose.

could be obtained from lignocellulosic materials by enzymatic hydrolysis. ${ }^{17,34}$ In this work, the effects of enzyme digestion time and enzyme dosage on the production of XOS from the hemicelluloses of the dissolving pulp were investigated. The yield of the XOS under different reaction conditions is shown in Fig. 3. Overall, when the enzymatic hydrolysis was conducted at $50 \mathrm{IU}$ $\mathrm{g}^{-1}$ substrate, the yield of the XOS gradually increased with the extending of the digestion time, indicating that relatively long reaction time could be used to improve the yield of XOS. However, as the enzyme concentration increased from 80 to 150 $\mathrm{IU} \mathrm{g}^{-1}$ substrate, the XOS yield dramatically increased in the first $8 \mathrm{~h}$, and then it decreased to some degree. This may result from the inhibition of the end-products to xylanase activity and the conversion of XOS to xylose. ${ }^{11,17,35}$ As shown in Fig. 3, the hydrolysis rate and yield of XOS significantly increased with the enzyme concentration varied from 50 to $120 \mathrm{IU} \mathrm{g}^{-1}$ substrate. Samanta and Akpinar et al. ${ }^{34,36}$ also respectively found that the xylan hydrolysis yield and rate increased with the enzyme dosage. However, the yield of XOS was almost unchanged when the enzyme concentration further increased from 120 to $150 \mathrm{IU}$ $\mathrm{g}^{-1}$ substrate. Similar results had been observed by Yang et al. ${ }^{17}$ when triploid Populas tomentosa was used to prepare XOS. It was probably because the ability of enzyme protein to bind its substrate reached a plateau at a certain enzyme concentration. ${ }^{37}$ Based on the results obtained, the highest XOS yield (42.96\%) from enzymatic hydrolysis was achieved at $120 \mathrm{IU} \mathrm{g}^{-1}$ substrate enzyme loading for $8 \mathrm{~h}$.

The yields of XOS (X2-X6) and xylose as a function of reaction time under the optimal enzymatic dosage (120 $\mathrm{IU} \mathrm{g}^{-1}$

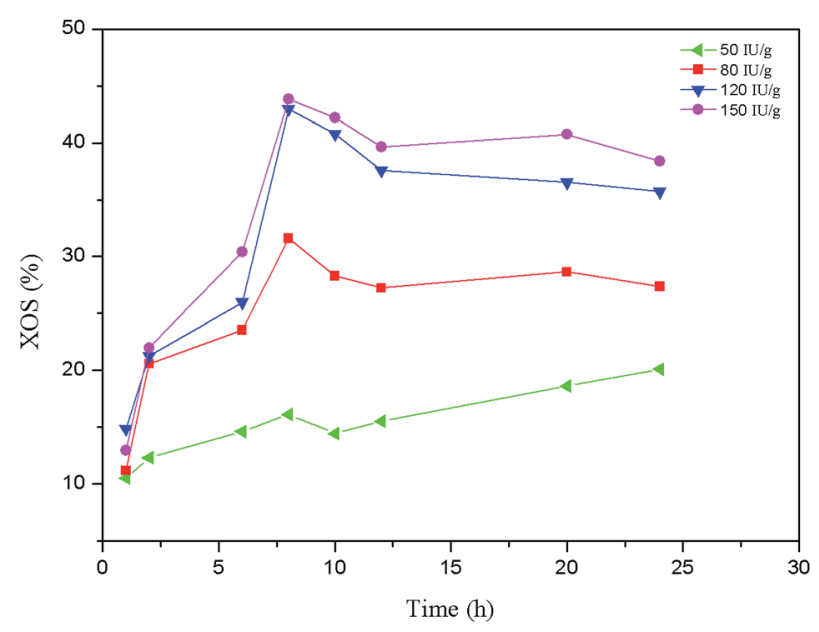

Fig. 3 Effect of enzyme concentration on the yield of XOS. 

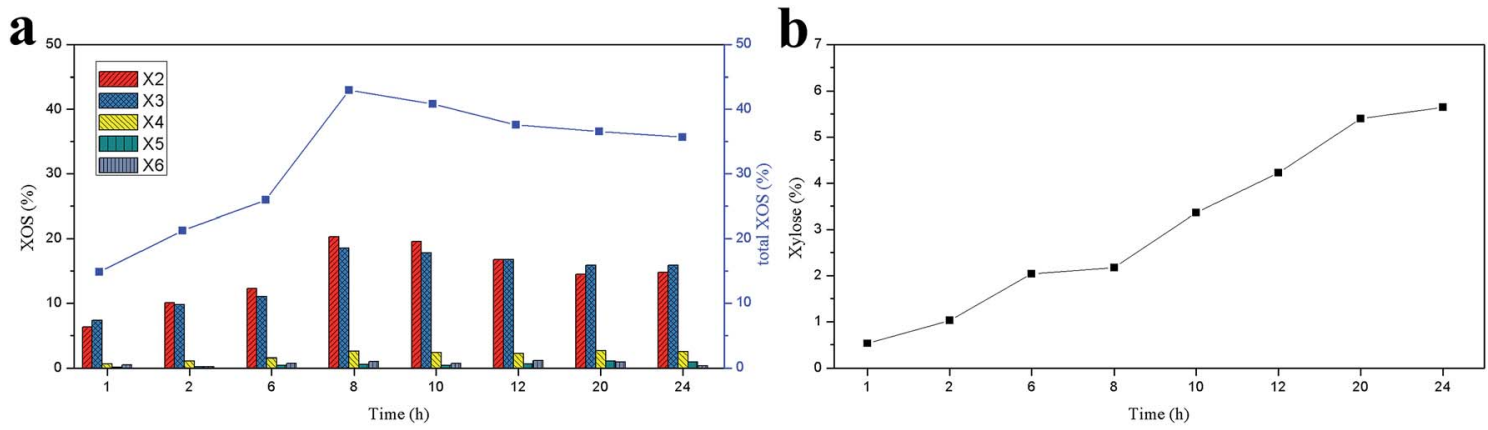

Fig. 4 Effect of reaction time on the yields of XOS (a) and xylose (b) under the optimum enzyme dosage.

substrate) are shown in Fig. 4. As illustrated in Fig. 4a, the XOS of the enzymatic hydrolysate was mainly composed of $\mathrm{X} 2$ and $\mathrm{X} 3$, and only a small quantity of $\mathrm{X} 4, \mathrm{X} 5$, and $\mathrm{X} 6$ was detected. Furthermore, the XOS yield gradually increased with the enzyme digestion time extended from 1 to $8 \mathrm{~h}$, and the highest yield of X2 (20.32\%) and X3 (18.56\%) was achieved at $8 \mathrm{~h}$. When the enzyme digestion time further extended, the yield of $\mathrm{X} 2$ and $\mathrm{X} 3$ decreased continually but changed slightly after $12 \mathrm{~h}$. In addition, the yields of X4, X5, and X6 changed slightly, and similar results had been reported by Bian et al. ${ }^{38}$ The xylose in the hydrolysate was also detected and shown in Fig. 4b. A small amount of xylose was observed in the enzymatic hydrolysate of hemicelluloses, and its content increased significantly with the enzyme digestion time. This suggested that the xylanase employed in this work contained a large amount of endo-xylanase and few xylosidase and/or exo-xylanase. ${ }^{39}$ Most of the endo-xylanase is used to degrade of the xylan main chain to XOS. ${ }^{5}$ When the enzyme digestion time was greater than $8 \mathrm{~h}$, the yield of xylose increased rapidly. This result was in accord with the decreasing of XOS yield after $8 \mathrm{~h}$. Clearly, a small quantity of XOS was degraded to xylose by xylosidase. ${ }^{35}$

\subsection{Comparison of the acid hydrolysis and enzymatic hydrolysis}

For acid hydrolysis, generally, a relatively high temperature and corrosion-resistant equipment may be required due to the utilization of sulfuric acid. In contrast, the reaction condition for enzymatic hydrolysis was mild but relatively long reaction time was needed. However, the XOS yield from the acid hydrolysis and enzymatic hydrolysis was similar, and the XOS yield from acid hydrolysis $(45.18 \%)$ was slightly higher than that from enzymatic hydrolysis (42.96\%). Furthermore, it should be noted that the XOS from the acid hydrolysis of hemicelluloses were mainly consisted of X6, which accounted for $47 \%$ of XOS, and a quantity of $\mathrm{X} 2, \mathrm{X} 3, \mathrm{X} 4$, and $\mathrm{X} 5$ were also contained in the hydrolysate. However, $\mathrm{X} 2$ and $\mathrm{X} 3$ were the major ingredients in the enzymatic hydrolysate, which took up 47.3 and $43.25 \%$ of the XOS, respectively. Additionally, the xylose yield from the enzymatic hydrolysis was much lower than that from the acid hydrolysis. These suggested that the corresponding enzymatic hydrolysis or acid hydrolysis method can be used to obtain the optimal XOS yield according to the XOS distribution required.

\section{Conclusions}

The residual hemicelluloses extracted from the dissolving pulp, mainly consisted of $\beta$-D-Xylp units, were applied to produce XOS. The influences of acid hydrolysis and enzymatic hydrolysis of hemicelluloses on the production of XOS were evaluated. The acid hydrolysis performed with $1 \%$ sulfuric acid at $120{ }^{\circ} \mathrm{C}$ for 60 min produced the highest XOS yield of $45.18 \%$. Meanwhile, a maximum XOS yield of $42.96 \%$ was obtained with $120 \mathrm{IU} \mathrm{g}^{-1}$ substrate for $8 \mathrm{~h}$. Although the yields of XOS from the acid and enzymatic hydrolysis were similar, the main products of XOS in the hydrolysate were obviously different. The major ingredient of the XOS from acid hydrolysis was X6, while X2 and X3 were the main products of the enzymatic hydrolysis.

\section{Conflicts of interest}

The authors declare no competing interests.

\section{Acknowledgements}

This work was supported by the Fundamental Research Funds for the National Science Foundation of China for Key Project (31430092), the National Natural Science Foundation of China (31700518), National Key Research and Development Program of China (Grant no. 2017YFB0307903), and the Fundamental Research Funds for the Central Universities (2015ZCQ-CL-02).

\section{References}

1 A. A. Aachary and S. G. Prapulla, Corncob-induced endo-1,4$\beta$-d-xylanase of Aspergillus oryzae MTCC 5154: production and characterization of xylobiose from glucuronoxylan, $J$. Agric. Food Chem., 2008, 56, 3981-3988.

2 H. Mäkeläinen, S. Forssten, M. Saarinen, J. Stowell, N. Rautonen and A. Ouwehand, Xylo-oligosaccharides enhance the growth of bifidobacteria and Bifidobacterium lactis in a simulated colon model, Benefic. Microbes, 2010, 1, 81-91.

3 F. Peng, P. Peng, F. Xu and R. C. Sun, Fractional purification and bioconversion of hemicelluloses, Biotechnol. Adv., 2012, 30, 879-903. 
4 A. A. Aachary and S. G. Prapulla, Xylooligosaccharides (XOS) as an Emerging Prebiotic: Microbial Synthesis, Utilization, Structural Characterization, Bioactive Properties, and Applications, Compr. Rev. Food Sci. Food Saf., 2011, 10, 2-16.

5 A. F. A. Carvalho, P. d. O. Neto, D. F. da Silva and G. M. Pastore, Xylo-oligosaccharides from lignocellulosic materials: Chemical structure, health benefits and production by chemical and enzymatic hydrolysis, Food Res. Int., 2013, 51, 75-85.

6 Y. C. Chung, C. K. Hsu, C. Y. Ko and Y. C. Chan, Dietary intake of xylooligosaccharides improves the intestinal microbiota, fecal moisture, and $\mathrm{pH}$ value in the elderly, Nutr. Res., 2007, 27, 756-761.

7 M. Kajihara, S. Kato, M. Konishi, Y. Yamagishi, Y. Horie and H. Ishii, Xylooligosaccharide decreases blood ammonia levels in patients with liver cirrhosis, Am. J. Gastroenterol., 2000, 95, 2514.

8 C. Grootaert, J. A. Delcour, C. M. Courtin, W. F. Broekaert, W. Verstraete and T. V. D. Wiele, Microbial metabolism and prebiotic potency of arabinoxylan oligosaccharides in the human intestine, Trends Food Sci. Technol., 2007, 18, 64-71.

9 J. Wang, X. P. Yuan, B. G. Sun, Y. P. Cao, Y. Tian and C. T. Wang, On-line separation and structural characterisation of feruloylated oligosaccharides from wheat bran using HPLC-ESI-MSn, Food Chem., 2009, 115, 1529-1541.

10 X. Xiao, C. Z. Wang, J. Bian and R. C. Sun, Optimization of bamboo autohydrolysis for the production of xylooligosaccharides using response surface methodology, RSC Adv., 2015, 5, 106219-106226.

11 C. Álvarez, A. González, M. J. Negro, I. Ballesteros, J. M. Oliva and F. Sáez, Optimized use of hemicellulose within a biorefinery for processing high value-added xylooligosaccharides, Ind. Crops Prod., 2017, 99, 41-48.

12 Q. Lin, H. Li, J. Ren, A. Deng, W. Li, C. Liu and R. Sun, Production of xylooligosaccharides by microwave-induced, organic acid-catalyzed hydrolysis of different xylan-type hemicelluloses: Optimization by response surface methodology, Carbohydr. Polym., 2017, 157, 214-225.

13 M. C. R. Mano, I. A. Neri-Numa, J. B. da Silva, B. N. Paulino, M. G. Pessoa and G. M. Pastore, Oligosaccharide biotechnology: an approach of prebiotic revolution on the industry, Appl. Microbiol. Biotechnol., 2018, 102, 17-37.

14 P. Vejdovszky, J. Oberlerchner, T. Zweckmair, T. Rosenau and A. Potthast, Preparation and Analysis of Cello- and Xylooligosaccharides, Cellulose Chemistry and Properties: Fibers, Nanocelluloses and Advanced Materials, Springer, Cham, 2015, pp. 53-92.

15 J. Bian, P. Peng, F. Peng, X. Xiao, F. Xu and R. C. Sun, Microwave-assisted acid hydrolysis to produce xylooligosaccharides from sugarcane bagasse hemicelluloses, Food Chem., 2014, 156, 7-13.

16 F. Mandelli, L. B. Brenelli, R. F. Almeida, R. Goldbeck, L. D. Wolf, Z. B. Hoffmam and F. M. Squina, Simultaneous production of xylooligosaccharides and antioxidant compounds from sugarcane bagasse via enzymatic hydrolysis, Ind. Crops Prod., 2014, 52, 770-775.

17 H. Yang, K. Wang, X. Song and F. Xu, Production of xylooligosaccharides by xylanase from Pichia stipitis based on xylan preparation from triploid Populas tomentosa, Bioresour. Technol., 2011, 102, 7171-7176.

18 D. J. Rose and G. E. Inglett, Production of feruloylated arabinoxylooligosaccharides from maize (Zea mays) bran by microwave-assisted autohydrolysis, Food Chem., 2010, 119, 1613-1618.

19 R. Yang, S. Xu, Z. Wang and W. Yang, Aqueous extraction of corncob xylan and production of xylooligosaccharides, $L W T$ Food Sci. Technol., 2005, 38, 677-682.

20 M. J. Vazquez, J. L. Alonso, H. Dominguez and J. C. Parajo, Xylooligosaccharides: manufacture and applications, Trends Food Sci. Technol., 2000, 11, 387-393.

21 C. Tian, L. Q. Zheng, Q. X. Miao, C. Y. Cao and Y. H. Ni, Improving the reactivity of kraft-based dissolving pulp for viscose rayon production by mechanical treatments, Cellulose, 2014, 21, 3647-3654.

22 G. Schild and H. Sixta, Sulfur-free dissolving pulps and their application for viscose and lyocell, Cellulose, 2011, 18, 11131128.

23 L. P. Christov, M. Akhtar and B. A. Prior, The potential of biosulfite pulping in dissolving pulp production, Enzyme Microb. Technol., 1998, 23, 70-74.

24 D. J. Mozdyniewicz, G. Schild and H. Sixta, Alkaline steeping of dissolving pulp. Part II: Soluble compounds in the press lye, Cellulose, 2014, 21, 2889-2900.

$25 \mathrm{H}$. Zhang, X. Zhou, Y. Xu and S. Yu, Production of Xylooligosaccharides from Waste Xylan, Obtained from Viscose Fiber Processing, by Selective Hydrolysis Using Concentrated Acetic Acid, J. Wood Chem. Technol., 2016, 37, 1-9.

26 Y. Zhang, G. Yu, B. Li, X. Mu, H. Peng and H. Wang, Hemicellulose isolation, characterization, and the production of xylo-oligosaccharides from the wastewater of a viscose fiber mill, Carbohydr. Polym., 2016, 141, 238-243.

27 A. Sluiter, B. Hames, R. Ruiz, C. Scarlata, J. Sluiter, D. Templeton, D. Crocker, Determination of structural carbohydrates and lignin in biomass, Laboratory Analytical Procedure, 2008, vol. 1617, pp. 1-16.

28 H. Yang, K. Wang, F. Xu, R. Sun and Y. Lu, $\mathrm{H}_{2} \mathrm{SO}_{4}$-Catalyzed Hydrothermal Pretreatment of Triploid Poplar to Enhance Enzymatic Hydrolysis, Ind. Eng. Chem. Res., 2012, 51, 11598-11604.

29 S. L. Sun, J. L. Wen, M. G. Ma and R. C. Sun, Successive alkali extraction and structural characterization of hemicelluloses from sweet sorghum stem, Carbohydr. Polym., 2013, 92, 2224-2231.

30 J. C. Parajó, G. Garrote, J. M. Cruz and H. Dominguez, Production of xylooligosaccharides by autohydrolysis of lignocellulosic materials, Trends Food Sci. Technol., 2004, 15, 115-120.

31 S. L. Sun, J. L. Wen, M. G. Ma, X. L. Song and R. C. Sun, Integrated biorefinery based on hydrothermal and alkaline 
treatments: Investigation of sorghum hemicelluloses, Carbohydr. Polym., 2014, 111, 663-669.

32 P. Gullon, M. J. Gonzalezmunoz and J. C. Parajo, Manufacture and prebiotic potential of oligosaccharides derived from industrial solid wastes, Bioresour. Technol., 2011, 102, 6112-6119.

33 X. Xiao, J. Bian, X. P. Peng, H. Xu, B. Xiao and R. C. Sun, Autohydrolysis of bamboo (Dendrocalamus giganteus Munro) culm for the production of xylo-oligosaccharides, Bioresour. Technol., 2013, 138, 63-70.

34 A. K. Samanta, N. Jayapal, A. P. Kolte, S. Senani, M. Sridhar, K. P. Suresh and K. T. Sampath, Enzymatic production of xylooligosaccharides from alkali solubilized xylan of natural grass (Sehima nervosum), Bioresour. Technol., 2012, 112, 199-205.

35 W. Gong, H. Zhang, L. Tian, S. Liu, X. Wu, F. Li and L. Wang, Determination of the modes of action and synergies of xylanases by analysis of xylooligosaccharide profiles over time using fluorescence-assisted carbohydrate electrophoresis, Electrophoresis, 2016, 37, 1640-1650.

36 O. Akpinar, O. Ak, A. Kavas, U. Bakir and L. Yilmaz, Enzymatic production of xylooligosaccharides from cotton stalks, J. Agric. Food Chem., 2007, 55, 5544-5551.

37 A. B. Boraston, B. W. Mclean, G. Chen, A. Li, R. A. J. Warren and D. G. Kilburn, Co-operative binding of triplicate carbohydrate-binding modules from a thermophilic xylanase, Mol. Microbiol., 2002, 43, 187-194.

38 J. Bian, F. Peng, X. P. Peng, P. Peng, F. Xu and R. C. Sun, Structural features and antioxidant activity of xylooligosaccharides enzymatically produced from sugarcane bagasse, Bioresour. Technol., 2013, 127, 236-241.

39 M. J. Vázquez, J. L. Alonso, H. Domínguez and J. C. Parajó, Enzymatic processing of crude xylooligomer solutions obtained by autohydrolysis of eucalyptus wood, Food Biotechnol., 2002, 16, 91-105. 